\title{
Determinants of body composition in breastfed infants using bioimpedance spectroscopy and ultrasound skinfolds-methods comparison
}

\author{
Zoya Gridneva', Anna R. Hepworth', Leigh C. Ward², Ching T. Lai', Peter E. Hartmann' and Donna T. Geddes
}

BACKGROUND: Accurate, noninvasive, and inexpensive methods are required to measure infant body composition. Ultrasound (US) and bioimpedance spectroscopy (BIS) have been validated in adults and introduced in pediatric populations. The aim of this study was to evaluate the performance of both methods in determining percentage fat mass (\%FM) in breastfed infants.

METHODS: \%FM of 2, 5, 9, and 12 mo-old healthy, breastfed term infants ( $n=58$ ) was calculated using BIS-derived total body water equations and skinfold equations then compared with reference models. Skinfolds were measured with US at two and four sites (biceps, suprailiac and/or triceps, and subscapular).

RESULTS: \%FM differed widely within and between methods, with the degree of variation affected by infant age/sex. Not a single method/equation was consistent with the distributions of appropriate reference values for all age/sex groups. Moderate number of matches with references values (13-24 out of 36) was seen for both types of equations. High number of matches (25-36) was seen for US skinfold-based equations. $\% F M$ values calculated from US and BIS were not significantly different $(P=0.35)$.

CONCLUSION: Both BIS and US are practical for predicting $\% F M$ in infants. BIS calculations are highly dependent upon an appropriate set of validated age-matched equations.

B ody composition (BC) in early life plays an important role in the programming of long-term health outcomes including obesity, type II diabetes, and cardiovascular disease (1). The majority of large studies reporting an association of infant development with disease later in life use anthropometric measurements or BMI to monitor growth that provide limited indices of adiposity as they fail to reflect body shape, fat distribution, and density.

The number of techniques available to assess infant $\mathrm{BC}$ is increasing. These measures have better accuracy than anthropometric measurements, but may be either time consuming, expensive, and invasive, expose infants to low levels of radiation (dual-energy X-ray absorptiometry and computed tomography), require the infant to be restrained (magnetic resonance imaging) or have weight restriction (air displacement plethysmography).

Bioelectrical impedance spectroscopy (BIS) is noninvasive and often used to estimate BC due to its ease of application and low cost. BIS measures the electrical impedance, or opposition to flow through the body tissues of a small harmless electric current. The measured impedance, corrected for the reactive component, known as electrical resistance is inversely and quantitatively related to the volume of conductive compartment which can be used to calculate total body water (TBW) and estimate fat-free mass (FFM) and fat mass (FM) (2). BIS provides reliable estimates of TBW in adults and equations have been developed for children and infants $(3,4)$. While in very young infants $(<5 \mathrm{mo})$ BIS is associated with poorer predictive performance that could be due to the higher conductivity of the infant's adipose tissue with its increased vascularization and water content, and rapidly changing hydration status caused by feeding patterns (4-6), small bias indicates that BIS is suitable for comparison between groups and for longitudinal studies (4).

Ultrasound (US) presents an alternative noninvasive and inexpensive technique to study infant BC. The US image is created by high frequency waves, which are attenuated during travel through tissue and reflected back to transducer (7). US can be used to measure depth and area of adipose and muscle tissue. Serial measurements have been made to evaluate the growth and development of term and preterm infant and to assess changes in BC in both groups $(8,9)$. Tracking BC with US is sensitive enough to detect breastmilk macronutrientrelated changes in adipose and muscle tissue accrued at the measurement sites in preterm infants (9). A modification of this method was utilized to measure subcutaneous tissue thickness (SCTT) in term infants, in place of traditional calipers. Calipers may disturb the infant (10) and mother while common issues such as movement and infant skin compressibility affect reliability (11). US offers a pain-free, more consistent solution and has been validated in adults against dual-energy

${ }^{1}$ School of Chemistry and Biochemistry, The University of Western Australia, Crawley, Australia; ${ }^{2}$ School of Chemistry and Molecular Biosciences, The University of Queensland, Brisbane, Australia. Correspondence: Zoya Gridneva (zgridneva@gmail.com)

Received 13 April 2016; accepted 30 August 2016; advance online publication 21 December 2016. doi:10.1038/pr.2016.235 


\section{Articles | Gridnevae tal.}

X-ray absorptiometry (12), utilized in assessment of BC of adults, adolescents, and infants (10).

While all $\mathrm{BC}$ measuring techniques have inherent limitations when used in infants and children, the combination of anthropometric measurements with US and/or BIS may offer relatively accurate, safe, and noninvasive assessment of BC, making them an attractive research tool for this population. The aim of this study was to compare these BIS and US assessments of $\mathrm{BC}$ of healthy term breastfed infants using a crosssectional approach to determine the accuracy and feasibility of both methods over a wide range of infant body masses.

\section{METHODS}

\section{Subjects}

Full term healthy breastfed infants ( $n=58 ; 31$ male and 27 female) of English speaking (predominantly Caucasian) mothers were recruited from the community, primarily from the Australian Breastfeeding Association. Inclusion criteria were: singletons; gestational age $\geq$ $37 \mathrm{wk}$; fully breastfed at 2 and $5 \mathrm{mo}$ and breastfed at the time of the study. Exclusion criteria were: infant health issues that could potentially influence growth and development and low maternal milk supply. Infants were measured once at either $2,5,9$, or 12 mo.

All mothers provided written informed consent to participate in the study, which was approved by The University of Western Australia, Human Research Ethics Committee.

\section{Design}

Study session. At each study session anthropometric (weight and length) and BIS measurements were taken prefeed; US skinfold measurements were taken postfeed. Where prefeed BIS were impractical, postfeed measurements were taken (13). Clothing was removed except for a dry diaper and a singlet.

Anthropometric measurements. A single weight and length measurement was performed on each infant. Infant's weight was determined by weighing before breastfeeding using Medela Electronic Baby Weigh Scales $( \pm 2.0 \mathrm{~g}$; Medela AG, Switzerland). Infant crown-heel length was measured once to the nearest $0.1 \mathrm{~cm}$ using nonstretch tape and headpiece and footpiece both applied perpendicular to the hard surface.

BIS measurements. Whole body bioimpedance (wrist to ankle) was measured using battery-operated Impedimed SFB7 bioelectrical impedance analyzer (ImpediMed, Brisbane, Queensland, Australia). This is a single channel, tetra-polar bioelectrical impedance spectrometer device capable of measuring reactance and resistance at 256 logarithmically spaced frequencies between 3 and $1,000 \mathrm{kHz}$. Before each session, the external calibration of the instrument was tested with a calibration RRC Test Cell (ImpediMed).

Infants were wearing a dry diaper and a singlet at the time of measurement. After wiping electrode sites with isopropyl alcohol, single

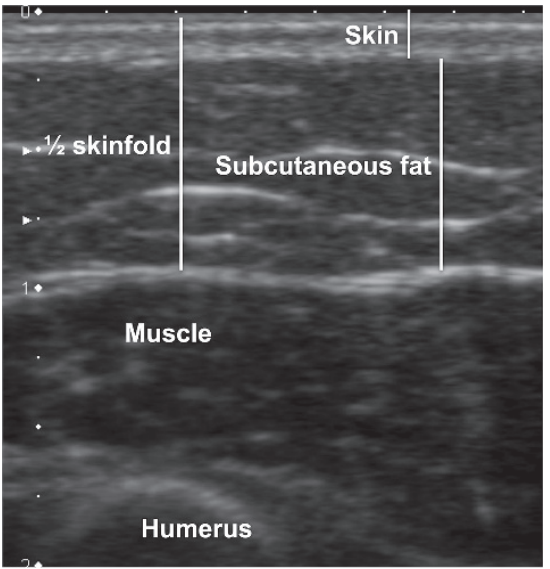

Figure 1. US image of infant triceps (upper arm) with skin, subcutaneous $\mathrm{fat}$, and muscle areas defined. The boundary between muscle and fat is marked by a bright line (fascia). A half skinfold measure is equal to the skin thickness plus the subcutaneous fat thickness and needs to be doubled for use in skinfold-based equation. Scale is presented on the left side of the scan with distance between 0 and $1=10 \mathrm{~mm}$.

Table 1. Subject characteristics presented as total and grouped by the infant age

\begin{tabular}{|c|c|c|c|c|c|}
\hline \multicolumn{6}{|c|}{ Age (mo) } \\
\hline & 2 & 5 & 9 & 12 & Total \\
\hline Characteristic & Mean \pm SD (Range) & Mean \pm SD (Range) & Mean \pm SD (Range) & Mean \pm SD (Range) & Mean \pm SD (Range) \\
\hline Age (months) & $\begin{array}{l}2.06 \pm 0.17^{a} \\
(1.80-2.37)\end{array}$ & $\begin{array}{c}5.08 \pm 0.22 \\
(4.60-5.37)\end{array}$ & $\begin{array}{c}9.17 \pm 0.35 \\
(8.13-9.77)\end{array}$ & $\begin{array}{c}12.34 \pm 0.23 \\
(11.90-12.67)\end{array}$ & $\begin{array}{c}7.35 \pm 3.85 \\
(1.80-12.67)\end{array}$ \\
\hline Body weight (kg) & $\begin{array}{l}5.458 \pm 0.581 \\
(4.420-6.335)\end{array}$ & $\begin{array}{c}7.170 \pm 1.088 \\
(5.674-9.510)\end{array}$ & $\begin{array}{c}8.997 \pm 0.779 \\
(7.683-10.605)\end{array}$ & $\begin{array}{c}9.604 \pm 0.968 \\
(7.170-11.085)\end{array}$ & $\begin{array}{c}7.909 \pm 1.813 \\
(4.420-11.085)\end{array}$ \\
\hline $\mathrm{R}_{50}(\Omega)^{\mathrm{b}}$ & $\begin{array}{c}646.8 \pm 105.5 \\
(516.1-862.7)\end{array}$ & $\begin{array}{c}702.3 \pm 93.7 \\
(584.1-855.6)\end{array}$ & $\begin{array}{c}685.5 \pm 85.9 \\
(582.8-811.5)\end{array}$ & $\begin{array}{c}652.0 \pm 45.2 \\
(576.4-727.0)\end{array}$ & $\begin{array}{c}672.8 \pm 86.1 \\
(516.1-862.7)\end{array}$ \\
\hline Biceps skinfold $(\mathrm{mm})^{c}$ & $\begin{array}{c}16.0 \pm 5.1 \\
(8.8-23.8)\end{array}$ & $\begin{array}{c}18.2 \pm 6.4 \\
(8.8-29.2)\end{array}$ & $\begin{array}{c}16.3 \pm 5.9 \\
(7.4-26.8)\end{array}$ & $\begin{array}{c}16.2 \pm 4.7 \\
(8.0-24.8)\end{array}$ & $\begin{array}{c}16.7 \pm 5.5 \\
(7.4-29.2)\end{array}$ \\
\hline Suprailiac skinfold $(\mathrm{mm})^{c}$ & $\begin{array}{l}10.9 \pm 3.5 \\
(7.0-19.8)\end{array}$ & $\begin{array}{c}14.6 \pm 4.7 \\
(10.2-24.6)\end{array}$ & $\begin{array}{l}13.5 \pm 4.0 \\
(9.0-20.6)\end{array}$ & $\begin{array}{l}11.3 \pm 4.6 \\
(4.8-19.6)\end{array}$ & $\begin{array}{c}12.4 \pm 4.3 \\
(4.8-24.6)\end{array}$ \\
\hline
\end{tabular}

aData expressed as mean \pm SD and range. ${ }^{b} R_{50}(\Omega)$ - whole body resistance (ohm) measured at $50 \mathrm{kHz}$. ${ }^{\text {S }}$ kinfolds values presented in the table are double of the measurements that were acquired with the ultrasound. 
Table 2. Associations between sample and reference distributions ( $P$-values) established with one-sample Kolmogorov-Smirnov test

\begin{tabular}{|c|c|c|c|c|c|c|c|c|c|c|c|c|c|c|}
\hline Reference & Sex/age, & Brook/ & Brook/ & Durnin/ & Durnin/ & Johnston/ & Johnston/ & & & & & \multicolumn{3}{|c|}{ Lingwood, Lingwood, Lingwood } \\
\hline$\% \mathrm{FM}^{\mathrm{a}}$ & & Lohman & Siri & Lohman & Siri & Lohman & Siri & Slaughter & Bocage & Fjeld & Kushner & $6 \mathrm{wk}$ & $3 \mathrm{mo}$ & $4.5 \mathrm{mo}$ \\
\hline Method & & US/4SF & US/4SF & US/4SF & US/4SF & US/4SF & US/4SF & $\mathrm{US} / 2 \mathrm{SF}^{\mathrm{a}}$ & $\mathrm{BIS}^{\mathrm{a}}$ & BIS & BIS & BIS & BIS & BIS \\
\hline \multicolumn{15}{|l|}{ Butte, BFa (17) } \\
\hline $31.5 \pm 5.6$ & $F / 2$ & 0.003 & $0.32^{c}$ & $<0.001$ & 0.103 & $<0.001$ & 0.004 & $<0.001$ & $<0.001$ & $<0.001$ & 0.012 & $<0.001$ & $<0.001$ & $<0.001$ \\
\hline $30.2 \pm 4.0$ & $\mathrm{M} / 2$ & $<0.001$ & 0.16 & $<0.001$ & $<0.001$ & $<0.001$ & $<0.001$ & 0.005 & $<0.001$ & $<0.001$ & $<0.001$ & $<0.001$ & $<0.001$ & $<0.001$ \\
\hline $32.0 \pm 4.4$ & $\mathrm{~F} / 5$ & 0.66 & 0.12 & 0.050 & 0.45 & 0.002 & 0.17 & 0.002 & 0.001 & $<0.001$ & 0.84 & $<0.001$ & 0.003 & 0.015 \\
\hline $29.1 \pm 4.7$ & $\mathrm{M} / 5$ & 0.28 & 0.23 & $<0.001$ & 0.14 & $<0.001$ & 0.052 & 0.19 & 0.065 & $<0.001$ & 0.75 & 0.094 & 0.39 & 0.51 \\
\hline $28.8 \pm 5.0$ & $F / 9$ & 0.96 & 0.32 & 0.15 & 0.27 & 0.002 & 0.49 & 0.034 & 0.55 & $<0.001$ & 0.017 & 0.022 & $<0.001$ & $<0.001$ \\
\hline $25.7 \pm 5.2$ & $\mathrm{M} / 9$ & 0.52 & 0.033 & 0.028 & 0.66 & 0.014 & 0.41 & 0.90 & 0.29 & $<0.001$ & 0.44 & $<0.001$ & $<0.001$ & $<0.001$ \\
\hline $27.6 \pm 4.3$ & $F / 12$ & 0.57 & 0.16 & 0.37 & 0.36 & 0.004 & 0.91 & 0.57 & 0.004 & $<0.001$ & 0.021 & 0.007 & $<0.001$ & $<0.001$ \\
\hline $25.6 \pm 4.0$ & $M / 12$ & 0.39 & 0.15 & $<0.001$ & 0.42 & $<0.001$ & 0.16 & 0.24 & 0.27 & 0.006 & 0.81 & $<0.001$ & $<0.001$ & $<0.001$ \\
\hline \multicolumn{15}{|l|}{ Butte, Ba (15) } \\
\hline $32.5 \pm 6.2$ & $\mathrm{~F} / 2$ & 0.002 & 0.16 & $<0.001$ & 0.045 & $<0.001$ & 0.002 & $<0.001$ & $<0.001$ & $<0.001$ & 0.011 & $<0.001$ & $<0.001$ & $<0.001$ \\
\hline $31.7 \pm 3.5$ & $M / 2$ & $<0.001$ & 0.014 & $<0.001$ & $<0.001$ & $<0.001$ & $<0.001$ & $<0.001$ & $<0.001$ & $<0.001$ & $<0.001$ & $<0.001$ & $<0.001$ & $<0.001$ \\
\hline $32.3 \pm 4.4$ & $\mathrm{~F} / 5$ & 0.59 & 0.16 & 0.039 & 0.52 & 0.001 & 0.13 & $<0.001$ & $<0.001$ & $<0.001$ & 0.92 & $<0.001$ & 0.001 & 0.009 \\
\hline $31.1 \pm 3.9$ & $\mathrm{M} / 5$ & 0.031 & 0.87 & $<0.001$ & 0.008 & $<0.001$ & 0.001 & 0.012 & 0.002 & $<0.001$ & 0.23 & 0.003 & 0.053 & 0.096 \\
\hline $27.8 \pm 4.6$ & $\mathrm{~F} / 9$ & 1.00 & 0.14 & 0.37 & 0.12 & 0.008 & 0.85 & 0.12 & 0.66 & $<0.001$ & 0.003 & 0.004 & $<0.001$ & $<0.001$ \\
\hline $27.8 \pm 4.8$ & $\mathrm{M} / 9$ & 0.11 & 0.28 & 0.002 & 0.21 & $<0.001$ & 0.078 & 0.37 & 0.023 & $<0.001$ & 0.29 & 0.012 & 0.002 & 0.009 \\
\hline $26.6 \pm 4.7$ & $\mathrm{~F} / 12$ & 0.66 & 0.11 & 0.67 & 0.17 & 0.025 & 0.97 & 0.90 & 0.023 & $<0.001$ & 0.040 & 0.003 & $<0.001$ & $<0.001$ \\
\hline $25.4 \pm 3.8$ & $\mathrm{M} / 12$ & 0.43 & 0.11 & $<0.001$ & 0.52 & $<0.001$ & 0.20 & 0.20 & 0.32 & 0.007 & 0.79 & $<0.001$ & $<0.001$ & $<0.001$ \\
\hline \multicolumn{15}{|l|}{ Fomon (21) } \\
\hline $21.1 \pm 4.4$ & $\mathrm{~F} / 2$ & 0.004 & $<0.001$ & 0.004 & $<0.001$ & 0.24 & $<0.001$ & 0.084 & 0.66 & $<0.001$ & 0.45 & 0.32 & 0.23 & 0.49 \\
\hline $19.9 \pm 4.1$ & $\mathrm{M} / 2$ & 0.015 & $<0.001$ & 0.21 & 0.002 & 0.038 & 0.015 & 0.004 & 0.24 & $<0.001$ & 0.26 & 0.024 & 0.11 & 0.031 \\
\hline $26.0 \pm 4.3$ & $\mathrm{~F} / 5$ & 0.048 & $<0.001$ & 0.22 & 0.002 & 0.38 & 0.048 & 0.94 & 0.55 & $<0.001$ & $<0.001$ & 0.27 & 0.038 & 0.078 \\
\hline $25.3 \pm 3.9$ & $\mathrm{M} / 5$ & 0.76 & $<0.001$ & 0.026 & 0.34 & 0.005 & 0.82 & 0.37 & 0.98 & $<0.001$ & 0.20 & 0.13 & 0.084 & 0.49 \\
\hline $25.0 \pm 5.0$ & $\mathrm{~F} / 9$ & 0.49 & 0.013 & 0.67 & 0.003 & 0.23 & 0.15 & 0.73 & 0.050 & 0.044 & $<0.001$ & $<0.001$ & $<0.001$ & $<0.001$ \\
\hline $24.0 \pm 5.2$ & $\mathrm{M} / 9$ & 0.66 & 0.004 & 0.082 & 0.24 & 0.033 & 0.61 & 0.42 & 0.70 & 0.005 & 0.21 & $<0.001$ & $<0.001$ & $<0.001$ \\
\hline $23.7 \pm 3.7$ & $F / 12$ & 0.25 & 0.004 & 0.61 & 0.002 & 0.56 & 0.12 & 0.39 & 0.19 & 0.017 & 0.12 & $<0.001$ & $<0.001$ & $<0.001$ \\
\hline $22.5 \pm 3.6$ & $\mathrm{M} / 12$ & 0.77 & 0.004 & 0.036 & 0.31 & 0.005 & 0.86 & 0.034 & 0.47 & 0.46 & 0.20 & $<0.001$ & $<0.001$ & $<0.001$ \\
\hline \multicolumn{15}{|l|}{ Fields (22) } \\
\hline $24.0 \pm 3.7$ & $\mathrm{~F} / 2$ & 0.18 & $<0.001$ & 0.16 & $<0.001$ & 0.027 & 0.009 & 0.86 & 0.054 & $<0.001$ & 0.48 & 0.22 & 0.33 & 0.013 \\
\hline $22.7 \pm 4.3$ & $\mathrm{M} / 2$ & 0.50 & $<0.001$ & 0.003 & 0.12 & $<0.001$ & 0.50 & 0.21 & 0.005 & $<0.001$ & 0.010 & 0.18 & 0.20 & 0.002 \\
\hline $27.7 \pm 5.0$ & $\mathrm{~F} / 5$ & 0.22 & 0.005 & 0.56 & 0.022 & 0.12 & 0.22 & 0.43 & 0.38 & $<0.001$ & 0.013 & 0.11 & 0.24 & 0.35 \\
\hline $26.2 \pm 4.1$ & $\mathrm{M} / 5$ & 0.82 & 0.004 & 0.006 & 0.61 & 0.001 & 0.70 & 0.73 & 0.83 & $<0.001$ & 0.47 & 0.32 & 0.24 & 0.88 \\
\hline \multicolumn{15}{|l|}{ Roggero (18) } \\
\hline $22.4 \pm 4.0$ & $\mathrm{~F} / 2$ & 0.023 & $<0.001$ & 0.020 & $<0.001$ & 0.21 & $<0.001$ & 0.35 & 0.29 & $<0.001$ & 0.45 & 0.70 & 0.67 & 0.14 \\
\hline $24.7 \pm 4.0$ & $\mathrm{M} / 2$ & 0.27 & 0.006 & $<0.001$ & 0.37 & $<0.001$ & 0.094 & 0.94 & $<0.001$ & $<0.001$ & $<0.001$ & 0.009 & 0.011 & $<0.001$ \\
\hline $29.5 \pm 3.3$ & $\mathrm{~F} / 5$ & 0.64 & 0.004 & 0.36 & 0.040 & 0.008 & 0.68 & 0.045 & 0.022 & $<0.001$ & 0.060 & 0.005 & 0.18 & 0.54 \\
\hline $27.5 \pm 2.1$ & $\mathrm{M} / 5$ & 0.10 & 0.021 & $<0.001$ & 0.19 & $<0.001$ & 0.086 & 0.25 & 0.13 & $<0.001$ & 0.42 & 0.85 & 0.59 & 0.55 \\
\hline \multicolumn{15}{|l|}{ Gilchrist (19) } \\
\hline $23.0 \pm 4.3$ & Both/2 & 0.078 & $<0.001$ & 0.40 & 0.007 & 0.003 & 0.067 & 0.13 & 0.001 & $<0.001$ & 0.043 & 0.076 & 0.11 & $<0.001$ \\
\hline $28.3 \pm 4.1$ & Both/5 & 0.76 & 0.029 & 0.021 & 0.97 & $<0.001$ & 0.56 & 0.13 & 0.601 & $<0.001$ & 0.12 & 0.020 & 0.38 & 0.54 \\
\hline \multicolumn{15}{|l|}{ Carberry (16) } \\
\hline $27.8 \pm 4.5$ & Both/5 & 0.95 & 0.011 & 0.058 & 0.83 & $<0.001$ & 0.64 & 0.33 & 0.10 & $<0.001$ & 0.07 & 0.050 & 0.28 & 0.61 \\
\hline \multicolumn{15}{|l|}{ Bellu (20) } \\
\hline $23.8 \pm 3.1$ & Both/12 & 0.14 & $<0.001$ & 0.11 & 0.018 & 0.001 & 0.15 & 0.012 & 0.43 & $<0.001$ & 0.13 & $<0.001$ & $<0.001$ & $<0.001$ \\
\hline Matches/36 & & 30 & 17 & 22 & 24 & 10 & 27 & 27 & 22 & 2 & 24 & 12 & 16 & 13 \\
\hline
\end{tabular}


Articles | Gridneva et al.

Table 3. Percentage fat mass of breastfed infants aged 2 to 12 mo calculated with ultrasound and bioimpedance spectroscopy equations

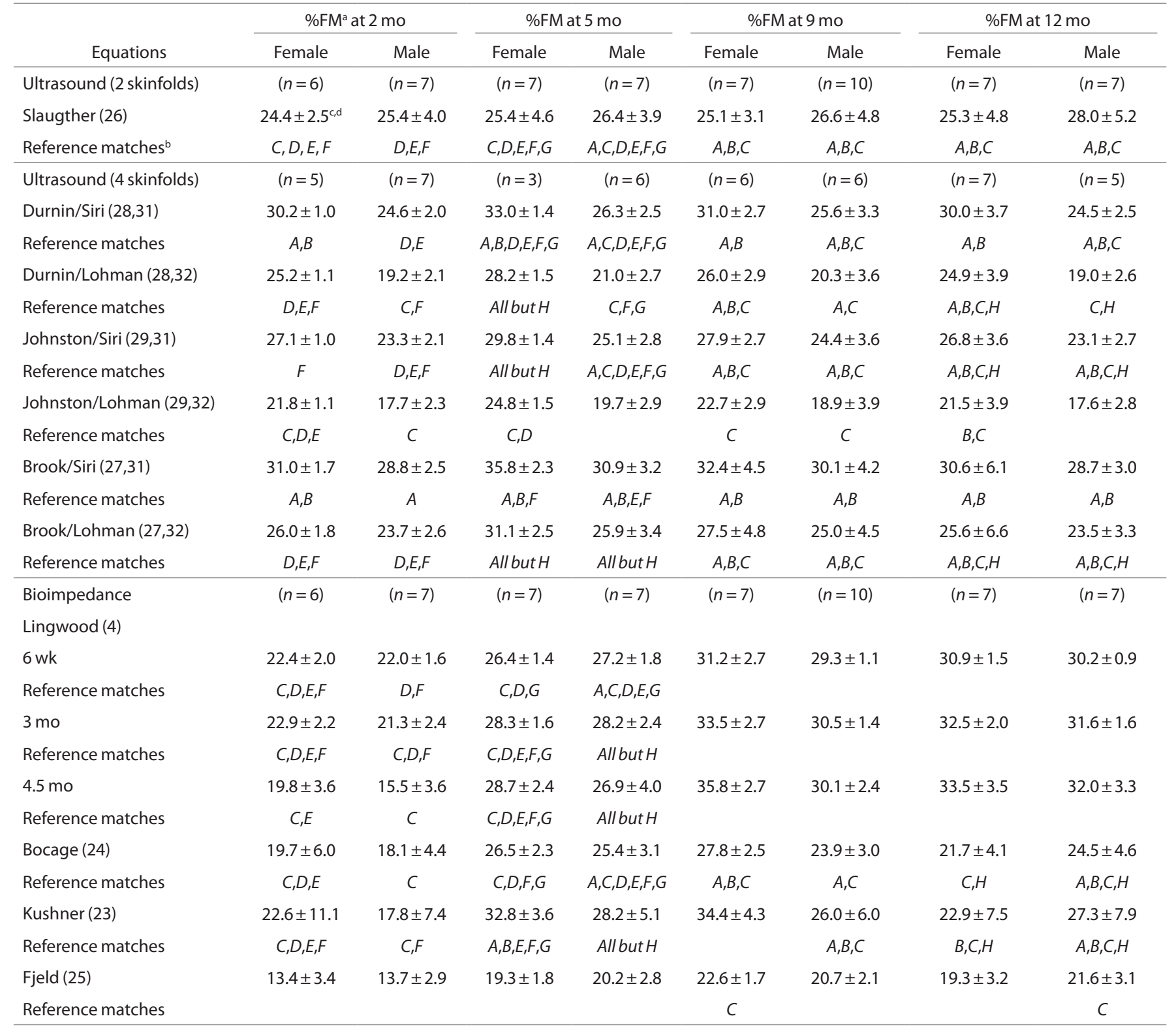

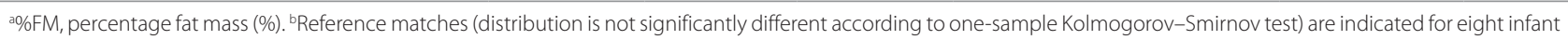
reference models: A - Butte mixed, 2000 (17); B - Butte breastfed only, 2000 in Gale et al. (15); C - Fomon, 2002 (21); D - Fields, 2011 (22); E - Roggero, 2010 (18); F - Gilchrist, 2007 (19); G - Carberry, 2010 (16); H - Bellu, 1997 (20). 'Data expressed as mean \pm SD. Percentage fat mass of breastfed boys and girls aged 2, 5, 9 and 12 mo calculated with various ultrasound and bioimpedance spectroscopy equations, presented together with the matches to the references.

$\mathrm{Ag}-\mathrm{AgCl}$ gel electrodes (ImpediMed) were applied to the skin on the right hand and foot. Two distal current drive electrodes were placed on the dorsal surface of the hand and the foot, at the metacarpalphalangeal and metatarsal-phalangeal joints; and two voltage sense electrodes were placed $3 \mathrm{~cm}$ proximal to the current electrodes. $3 \mathrm{M}$ Micropore surgical tape (3M Health Care, Neuss, Germany) was used to secure the electrodes in position. Electrodes were left on the limbs for the second series of measurements after the breastfeed. No direct contact was made with the infant's skin during the measurements and insulating material (cloth) was used to ensure no contact occurred between the infant's limbs or between the infant and the mother's hands. Series of measurements (pre or postfeed) consisted of 10-50 consecutive measurements taken within 1-2 min with infants in supine position on a nonconductive surface.

Collected data were transferred to a computer and analyzed by fitting the measured resistance and reactance at each frequency to a
Cole-Cole plot using Bioimp version 5.2.2.0 software (ImpediMed). All raw data were visually examined and measurements were analyzed with settings customized for infants to ensure goodness of fit as assessed by the standard error of the estimate as per Lingwood et al. (4): Td correction off; identification of the curve that most closely resembles a semicircle and setting the frequency range to cover this portion of the curve (upper/lower frequency limits of $1,000 / 12 \mathrm{kHz}$ ); rejection limit of 1\%; achieving standard error of the estimate $<1.0$ and then applying Td correction of 0 ). Values of resistance (ohm) at frequency of $50 \mathrm{kHz}\left(\mathrm{R}_{50}\right)$ were determined from the curve of best fit and averaged for analysis purposes. This frequency was chosen as $R_{50}$ is commonly used to predict TBW in empirically derived prediction equations (14).

US skinfold measurements. Single measurements of SCTT were taken on the left side of the body with minimal compression. US scans of four anatomical sites (biceps, subscapular, suprailiac, and triceps) 


\section{Body composition of breastfed infants}
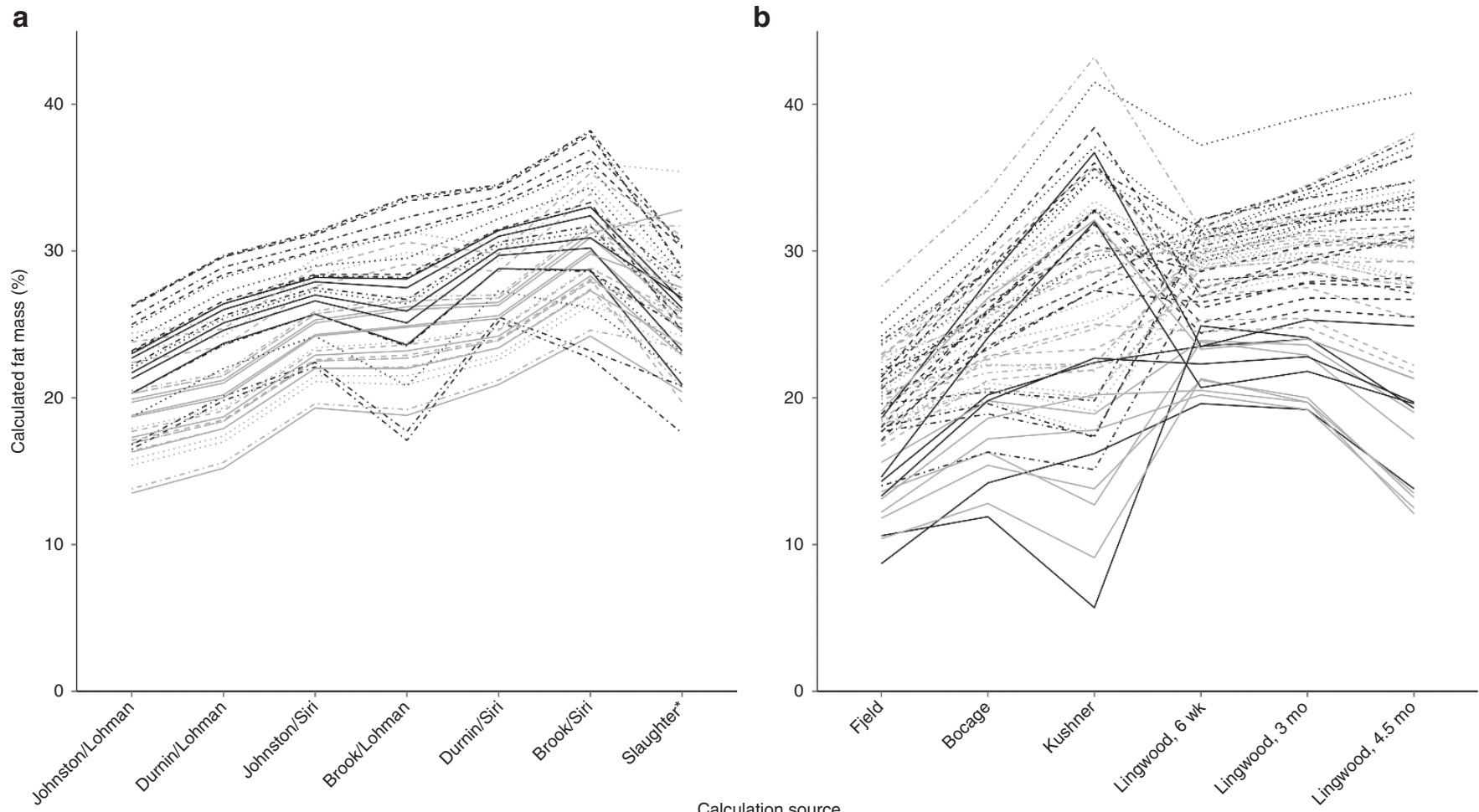

Figure 2. Calculated percentage fat mass of individual infants $(n=58)$ using (a) ultrasound (US) skinfolds or (b) bioimpedance-based total body water equations ordered from lowest to highest within a method. Each line represents an individual infant and connects all available percentage fat measurements for that infant to illustrate the differences between values calculated with the various equations. US four skinfolds: Johnston/Lohman; Durnin/ Lohman; Johnston/Siri; Brook/Lohman; Durnin/Siri; Brook/Siri. US two skinfolds: Slaughter. Bioelectrical impedance spectroscopy: Fjeld; Bocage; Kushner; and Lingwood, 6 wk; Lingwood, 3 mo; Lingwood, 4.5 mo. Lines are grouped as: females - black; males - gray; - 2 mo-old infants, - - 5 mo-old,. .99 moold $\cdot-\cdot \cdot 12$ mo-old

Table 4. Comparative performance of all ultrasound and bioimpedance spectroscopy equations

\begin{tabular}{lcc}
\hline Equation & Method & \%FM(Mean \pm SD) \\
\hline Fjeld (25) & BIS $^{\mathrm{a}}$ & $19.0 \pm 4.0^{\mathrm{b}, \mathrm{c}}$ \\
Johnston/Lohman (29) & US/4SF & $20.6 \pm 3.5^{\mathrm{d}}$ \\
Durnin/Lohman (28,32) & US/4SF & $22.9 \pm 4.1^{\mathrm{d}}$ \\
Bocage (24) & BIS & $23.5 \pm 4.7^{\mathrm{c}}$ \\
Slaughter (26) & US/2SF & $25.9 \pm 4.1^{\mathrm{c}}$ \\
Johnston/Siri (29,31) & US/4SF & $26.0 \pm 3.2^{\mathrm{d}}$ \\
Brook/Lohman (27,32) & US/4SF & $26.0 \pm 4.3^{\mathrm{d}}$ \\
Kushner (23) & BIS & $26.5 \pm 8.1^{\mathrm{c}}$ \\
Lingwood 6 wk (4) & BIS & $27.7 \pm 3.7^{\mathrm{c}}$ \\
Lingwood 4,5 mo (4) & BIS & $28.1 \pm 7.0^{\mathrm{c}}$ \\
Durnin/Siri (28) & US/4SF & $28.1 \pm 3.8^{\mathrm{d}}$ \\
Lingwood 3 mo (4) & BIS & $28.8 \pm 4.5^{\mathrm{c}}$ \\
Brook/Siri (27,31) & US/4SF & $31.0 \pm 4.0^{\mathrm{d}}$ \\
\hline
\end{tabular}

aBIS, bioimpedance spectroscopy; \%FM, percentage fat mass (\%); US/2SF, ultrasound with two skinfolds; US/4SF, ultrasound with four skinfolds. 'Mean \pm SD of infant \%FM calculated on the raw data for the whole group using BIS and US equations and presented from the lowest to the highest value. ${ }^{c}(n=58) ;{ }^{d}(n=45)$.

were performed using the Aplio XG (Toshiba, Tokyo, Japan) machine and a high-resolution PLT-1204BX 14-8 MHz transducer (9). Sterile water-based Aquasonic 100 US transmission gel (Parker Laboratories, Fairfield, NJ) was placed between the probe and the infant's skin to ensure penetration of the US beam, enhance imaging and to minimize tissue compression. The SCTT (skin thickness and the skin-fat interface to fat-muscle interface distance that were easily defined on the scan) was measured directly from images on the screen using electronic calipers (12) (Figure 1). All of the measurements were performed by one experienced sonographer (DG) with previously reported high intraobserver reliability (9).

US skinfold measurements were doubled for the use in skinfold equations developed for SCTT measurement with skinfold calipers (11).

Equations and reference models. Equations and reference models were sourced from the literature. Equations for calculations of TBW, FFM, and \%FM using resistance $\left(\mathrm{R}_{50}, \Omega\right)$ and for calculations of body density and \%FM using skinfold thickness $(\mathrm{mm})$ measurements are presented in Table 6. The \%FM value calculated with six BIS-based and seven skinfold-based equations were compared with eight reference values data sets for \%FM, measured by various reference techniques (15-22).

All of the reference studies with the exception of Fomon (21) state that either all or a proportion of infants were breastfed. In Butte's study (15) infants $(n=40)$ were exclusively breastfed for 4 mo with only $38 \%$ still breastfed at 12 mo. Infants in Bellu's study (20) of 12 mo old infants $(n=26)$, were breastfed for at least 6 mo and were not at the time of the study. Infants in Roggero et al. (18) $(n=59)$, Fields et al. (22) $(n=160)$, and Gilchrist et al. (19) study $(n=80)$ were exclusively breastfed from birth to 6 mo at which point all three studies had ended. While infants $(n=30)$ in Carberry et al. study (16) were predominantly or exclusively breastfed, they were followed up to 4.5 mo only.

The broad variation in time points in the reference models made it difficult to compare both the references' and our time points. Combining the available references ensured that there is sufficient $\mathrm{BC}$ data to establish mean \pm SD values for several age/sex groups up to 12 mo. 


\section{Articles | Gridnevaetal.}

a

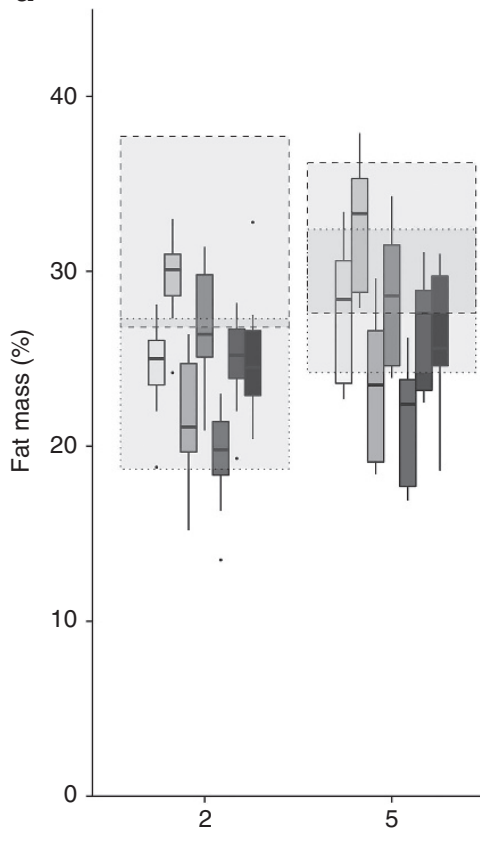

b

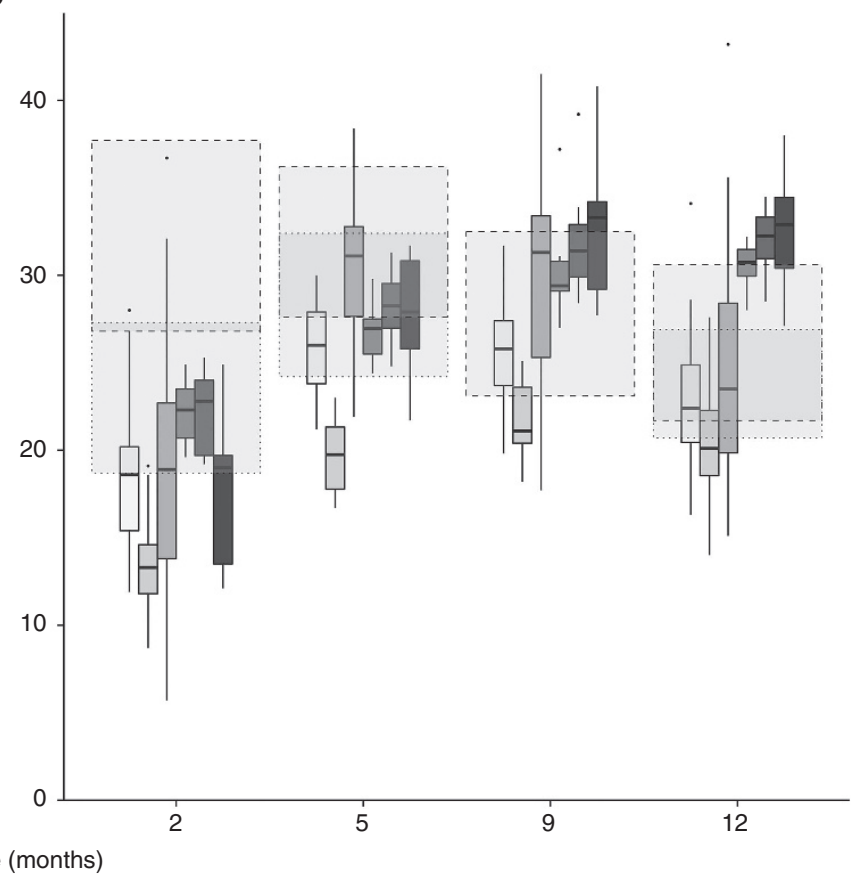

Figure 3. Distributions of infant percentage fat mass calculated using each of the (a) ultrasound (US) skinfolds or (b) bioimpedance-based total body water equations at four time points: $2 \mathrm{mo}(n=13), 5 \mathrm{mo}(n=14), 9 \mathrm{mo}(n=17)$, and $12 \mathrm{mo}(n=14)$, pooled by sex. US skinfolds equations represented by gray scale in the following order from left to right: Brook/Lohman; Brook/Siri; Durnin/Lohman; Durnin/Siri; Johnston/Lohman; Johnston/Siri; Slaughter (two skinfolds). Bioelectrical impedance spectroscopy equations represented by gray scale in the following order from left to right: Bocage; Fjeld; Kushner; and Lingwood, 6 wk; Lingwood, 3 mo; Lingwood, 4.5 mo. Rectangles are selected reference ranges (mean \pm SD): - - - Butte reported in Gale et al. (15) at all ages; $\cdots$... Gilchrist (19) at 2 and 5 mo, Bellu (20) at 12 mo.

Prediction equations were selected according to the following criteria: closest age match and predominantly Caucasian population. While it is recommended not to extrapolate from equations for older pediatric subjects to the early infant period, which is associated with chemical immaturity, it is not always possible to adapt even age-matched equations with the change in methodology as in case of using US to measure skinfolds. Therefore, several equations were tested and only few were chosen for further analysis. Those equations, not chosen produced erroneous results upon calculation or were discarded because of nonmatching variables.

Chosen BIA-based equations for TBW were established in infants and children of various ages $(4,23-25)$ then validated in healthy infants (4), as well as in well and malnourished children (25). Predicted TBW was converted to FFM using Butte et al. (17) age-appropriate hydration factors and \%FM was further calculated.

Chosen equations based on caliper skinfolds for \%FM and body density were established for use in children and adolescents (26-29); and evaluated in term and preterm infants (30). Predicted body density was converted to \%FM using both Siri (31) and Lohman (32) equations.

Details of the equations are given in Table 6.

\section{Statistical Analyses}

Statistical analysis was carried out using R-software package (version 2.9.0 for Mac OSX; R Foundation for Statistical Computing, Vienna, Austria). The R-packages nlme (version 3.1-96), multcomp (33), ggplot2 (34) were used for linear mixed effect models, Tukey's all pair comparisons, data exploration, and graphics respectively. Descriptive statistics are reported as mean \pm SD (range), model parameters as estimate $(95 \% \mathrm{CI})$. P-values $<0.05$ were considered statistically significant except where an adjustment for multiple comparisons false discovery rate was performed (35). Analysis was carried out as overall, by age/sex groups and by sex within age.

Infants were measured once at either $2,5,9$, and 12 mo as they were recruited for a larger study. Forty participants, 10 in each age group (to achieve a wider body mass spread), allowed for detection of an effect size of 0.5 . When 40 infants had been recruited, an uneven gender split caused us to extend recruitment to achieve similar group sizes and gender balance. Using $\alpha=0.05$, final recruitment of 58 participants gave the study power of 0.94 to detect an effect size of 0.3 (36).

One-sample Kolmogorov-Smirnov (KS) tests (37) were used to compare the \%FM data for each of the predictors with each of the eight reference distributions. Each age/sex group was compared with the most appropriate reference distributions. If no sex specific reference was available, pooled data were used. Where no SD was available in the reference model the SD was calculated as an average of SDs of the given age/sex groups of other reference models. The KS test requires that there be no ties in the data; 0.01 was added to one value when ties existed. $P$-values are not exact in those cases. Owing to the large number of comparisons, an adjustment for multiple comparisons false discovery rate was performed (35). The calculated values were considered not significantly different from the reference values at $P>0.018$ for US skinfold measurements and $P>0.024$ for BIS. The number of matches between reference and sample distributions was classified as low ( $0-12$ of possible 36 matches), moderate (13-24 matches) or high (25-36 matches).

Raw data $(n=58)$ was used for calculating averages to compare overall equations performances in the whole group. General linear hypothesis test (Tukey's all pair comparisons) was used to check for systematic differences between the equations. Some overall analyses were repeated after removing two equations with $<1 / 3$ of matches to the references.

$\mathrm{CV}$ s for each measurement were calculated from infants with data for all 13 equations $(n=45)$ omitting infants missing four skinfolds measurements $(n=13)$.

Linear mixed effects models with random intercept per participant were used to determine whether \%FM measurements differed systematically by equation and infant sex and/or age group. Where there were more than two levels of categorical variable, Tukey's all 


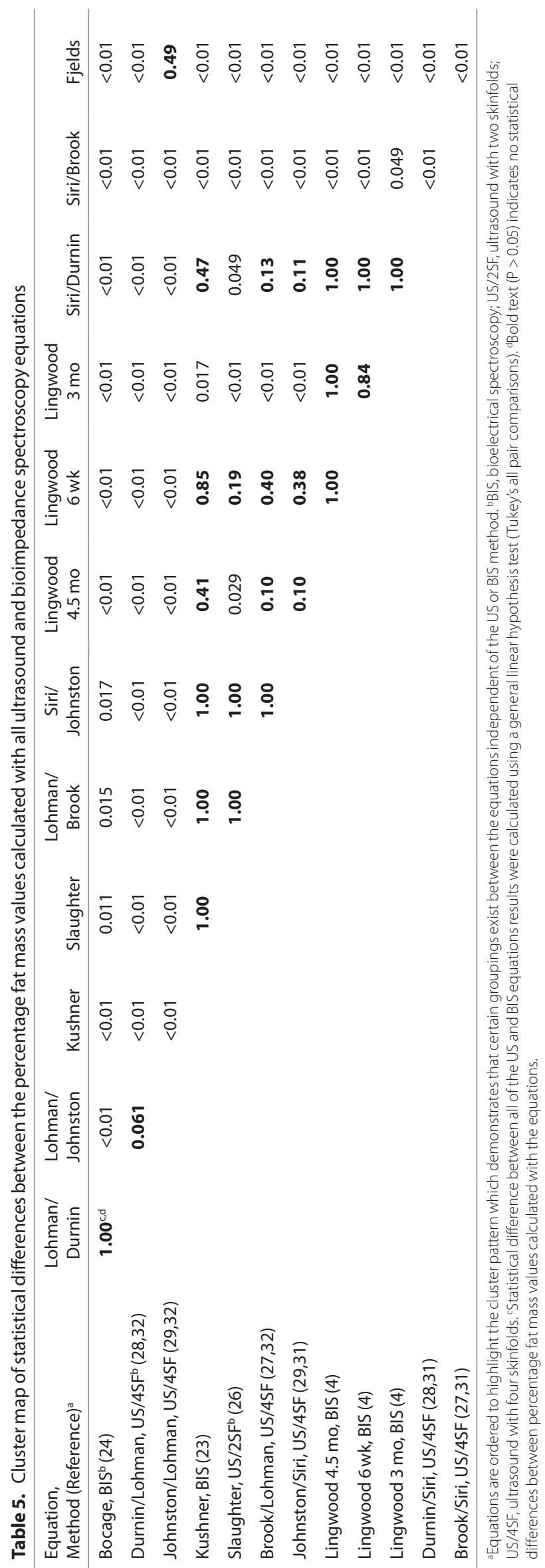

pair comparisons were used to determine which levels differed. Possible sex differences between methods were tested with interaction between sex and equation.

RESULTS

Subjects

Infants were two $(2.06 \pm 0.17, n=13)$, five $(5.08 \pm 0.22, n=$ $14)$, nine $(9.17 \pm 0.35, n=17)$ or $12(12.34 \pm 0.23, n=14) \mathrm{mo}$ of age at the time of measurement. Of the 58 infants, 54 were measured with BIS prefeed and four postfeed $(n=58)$. At the earlier stage of data collection only two skinfolds (triceps and subscapular) were measured with US, resulting in two skinfold measures for $n=58$ and four skinfolds measures for $n=45$. Subjects' characteristics are presented in Table 1.

Two 2 mo-old male infants were excluded from the study due to confirmed low maternal milk supply that could affect infant BC. One infant at the time of the visit was in second centile for weight and fifth for length according to WHO growth charts and had plateaued for $2 \mathrm{wk}$, later dropping to first centile for weight. The second infant was in fifth centile for both weight and length.

\section{Comparison of Sample and Reference Distribution}

Table 2 presents the probabilities that the sample distributions were drawn from each of the considered reference distributions. After an adjustment for false discovery rate values were considered not significantly different from the reference values at $P>0.018$ for US skinfold measurements and $P>0.024$ for BIS. Neither BIS nor US were consistent with distributions from appropriate reference values for all age/sex groups. A moderate number of matches (13-24 matches) with reference values were seen for both types of equations (three BISbased and two US skinfold-based). High number of matches (25-36 matches) was predominantly seen for US skinfoldbased equations (one BIS-based and four US skinfold-based).

\section{\% FM Calculated with BIS and US}

Calculated \%FM values displayed wide variation within and between US and BIS, with the degree of variation affected by both infant age and sex (Table 3). Distributions of \%FM calculated with two skinfolds matched with 27/36 reference values; use of four skinfolds gave between 10 and 30 matches. Figure 2 shows comparative performance of all of the equations for each infant. Table 4 presents the performance of all BIS and US skinfold equations in the whole group of infants (raw data, $n=58$ ). The Fjeld (BIS) and Johnston/Lohman (US) equations were excluded from further overall analysis as both were at the lower end of calculated \%FM and had the lowest number of matches $(<1 / 3)$ with the references.

\section{Effect of Sex on BC}

Overall, \%FM was $2.0 \%(0.013,3.9)$ lower in males $(P=0.036)$. When the equations were considered separately, significant sex differences were only seen for those based on four US skinfolds $(P<0.001$ for all) with the endpoints of the 95\% CIs between 2.00 and 7.08. Brook/Siri $(P=0.051)$, Brook/Lohman $(P=$ $0.050)$, Slaughter $(P=0.16)$ and all BIS equations $(P>0.075)$ 


\section{Articles | Gridnevae tal.}

Table 6. Published equations used in the study

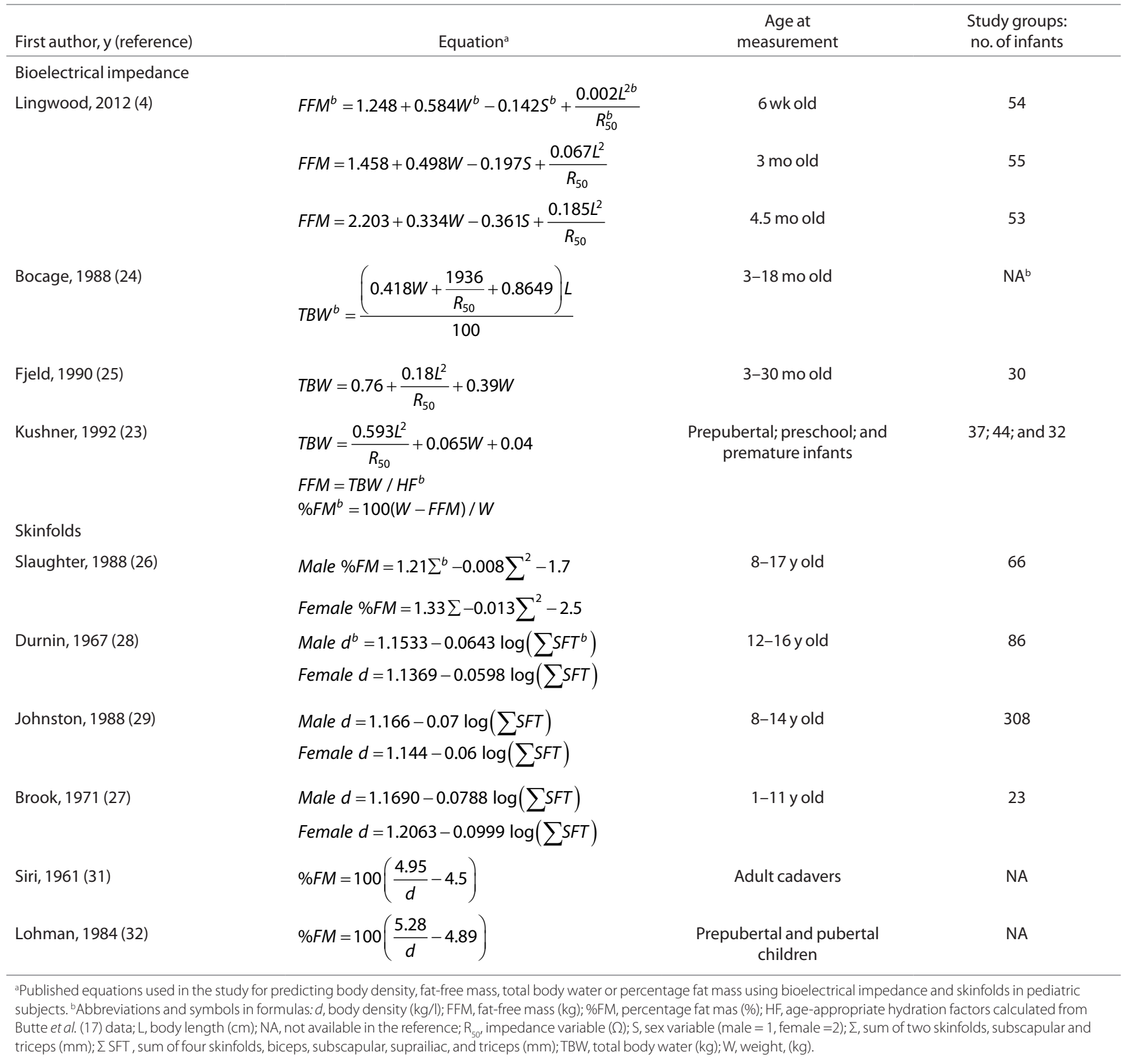

showed no significant difference in \%FM between the sexes (Figure 2).

\section{Effect of Age on BC}

Overall 2 mo-old infants had significantly lower \%FM than the 5, 9, and 12 mo-olds $(P<0.001)$ with the differences between this group and each of the other three nearly of the same magnitude (4.6-5.5\%) (Figure 2). In the detailed analysis, all BIS equations showed overall significant differences for age $(P \leq 0.001)$ while all US skinfold equations showed no significant differences $(P>0.34)$. Looking at differences between the age groups all three Lingwood equations showed progressive increase in \%FM between 2 and 5;2 and 9;2 and
12; 5 and 9; 5 and 12 mo $(P<0.001$ for all $)$ but not between 9 and 12 mo $(P>0.88)$. The Fjeld equation showed a progressive increase in \%FM between 2 and 5; 2 and 9; 2 and 12 mo $(P<0.001)$, but \%FM was not significantly different between 5 and $9 ; 5$ and 12 mo; 9 and 12 mo $(P>0.28)$. The Bocage equation showed progressive increase in \%FM between 2 and 5; 2 and 9 mo $(P<0.001)$; and 2 and 12 mo $(P=0.034)$, but $\% \mathrm{FM}$ was not significantly different between 5 and 9; 5 and $12 \mathrm{mo} ; 9$ and $12 \mathrm{mo}(P>0.33)$. The Kushner equation showed a progressive increase in \%FM only between 2 and $5(P=$ $0.002)$; and 2 and 9 mo $(P=0.005)$, but \%FM was not significant between 2 and 12; 5 and 9; 5 and 12; and 9 and 12 mo $(P \geq 0.28)$. 


\section{BIS and US Comparison}

BIS-based equations displayed greater variability than US skinfold-based with calculated CVs $(n=45)$ ranging from $15 \%$ to $34 \%$ and from $13 \%$ to $18 \%$ respectively. Overall $\% \mathrm{FM}$ was $0.34 \%(-0.37,1.04)$ lower when calculated with US skinfold equations $(P=0.35)$ than with BIS. Figure 3 illustrates performance of all 13 equations in different age groups in comparison to few references.

\section{Comparisons Between the Equations}

Table 5 presents a cluster map of statistical differences between the \%FM values calculated with all BIS and US equations and demonstrates that certain groupings exist between the equations independent of the method.

\section{DISCUSSION}

With increasing pediatric obesity, the focus of the research is on associations between early nutrition, $\mathrm{BC}$ and risk of future disease. BC assessment during early infancy, when the window of opportunity for intervention still exists, is crucial and reference data, particularly for breastfed infants is desperately needed. Our findings indicate that both BIS and US are practical for calculating \%FM in breastfed infants, but accuracy of prediction is highly dependent upon the use of validated agematched prediction equations.

A limited number of BC reference data exist for infants during the first year of life, particularly for breastfed infants whose FFM is significantly lower and \%FM is significantly higher compared with formula-fed infants (15). The major strength of our study was that all infants were breastfed at the time of measurements (to $12 \mathrm{mo}$ ); therefore this study describes the $\mathrm{BC}$ for infants fed according to WHO recommendations in the first year of life. We found that no single equation for calculation of \%FM by BIS and US allowed a match to the references across the first 12 mo therefore should these methods be used, it is important to make an informed selection of equations that will match preferred references for both sampling time points and sex (Tables 2 and 3 ).

Overall, we found no difference between US and BIS calculations of \%FM indicating that both methods are acceptable for measurements in the field. Further, there were more matches with reference values for US skinfold based equations (Table 2). Slaughter, a two skinfold method, had high level of matches with reference values without requiring additional calculations to determine \%FM (Siri or Lohman), as required with four skinfold equations, making it a very attractive tool for large studies. If the four skinfold method is chosen, a greater number of matches with reference values were achieved using the Siri \%FM equation vs Lohman \%FM equation (Tables 2 and 6) with the exception of Brook/Lohman. The Lohman \%FM equation is based on prepubertal and pubertal children BC (32), taking into account the lower bone-mineral and higher water content of this population, and was expected to provide more matches. The Siri \%FM equation, while it is based on adult cadaver BC (31), is the most widely used in both adult and pediatric populations and in this study provided more matches overall. The Lohman equation often underestimated \%FM, despite the fact that dermis and fat layers are not compressed with US, possibly making skinfold measurements larger than the caliper technique and resulting in lower body density and higher \%FM (38).

Examination of BIS equations showed Kushner (23) and Bocage (24) calculations to have the highest number of matches with the reference values, which is similar to that of US skinfolds with Durnin/Siri and Durnin/Lohman ((Table 2). There is also a trend that the equations that showed the most matches also covered a larger number of reference studies. It is possible that greater variations of estimated values of Kushner and Bocage increase the chance of overlapping with multiple distributions. Equations should be chosen to be age matched to the study population otherwise erroneous results are obtained as demonstrated by the performance of the Lingwood $6 \mathrm{wk}, 3$ mo and 4.5 mo equations at 9 and 12 mo where no matches were seen with any of the reference studies (Tables 2 and 3 ).

When we compare all tested equations for calculation of $\% \mathrm{FM}$ (irrespective of method) the majority gave significantly different values (Table 5). However, Lingwood $6 \mathrm{wk}$ equation was most likely to give comparable results to the other equations. No clustering was noted for the type of the method indicating that most of the variation in calculated values lies in the equation.

Infant sex is believed to influence BC with males having lower \%FM than females at some time points $(16,17)$, although a number of studies have failed to show this (18-20) or have not analyzed for it $(15,21,22)$. We showed that US (four skinfolds) was able to detect sex differences with the exception of Brook/Siri and Brook/Lohman yet BIS did not. The Bellu's study (20) using total body electrical conductivity, which is based on similar principles as BIS did not show sex differences and therefore the similarity in technique might explain our BIS results. Results from air displacement plethysmography are mixed but Butte (17) used a multicomponent model, which is considered more accurate.

$\%$ FM changes in the first year of life with gradual increase in first 6 mo followed by gradual decrease to 12 mo $(17,21)$. Age differences in \%FM are mixed with some studies reporting an overall significant increase in $\% \mathrm{FM}$ in the first 4 mo of life $(16,18,22)$ or no change between 2 and $3 ; 4$ or 5 mo (19); and detailed analysis between time points is not always available. In our study, only BIS were able to detect age differences and match them to literature. The Lingwood equations were the most sensitive to age producing statistically different values between most of the groups, with the other three BIS equations finding differences only between 2 mo and the remaining time points. The Bocage equation was established in 3-18 mo old infants but only detected age differences at $2 \mathrm{mo}$, as did Fjeld (3-30 mo old infants) and Kushner (premature infants to adults). The lack of age specific equations for skinfolds for the first 12 mo of life is an important part of why we were unable to detect age differences with US and further emphasizes the need for development of new multiple age specific equations covering the first year of life. 


\section{Articles | Gridnevae tal.}

We excluded two infants based on their growth and low maternal milk production. In the first infant BIS and US agreed, with a best age/sex fitted equation for \%FM for BIS (Lingwood, 3 mo) producing $11.1 \%$ and for US (Brook/Lohman) $17.5 \%$. In the second infant, the measurements were disparate with $14.9 \% \mathrm{FM}$ for BIS and $28.2 \% \mathrm{FM}$ for US. Interestingly, \%FM values based on US skinfolds were low in the first infant that plateaued for $2 \mathrm{wk}$ before the visit, but were normally distributed for the second infant. The large discrepancy for second infant might be related to the reduction in FFM. This is similar to preterm infants that at the time of estimated arrival often have greater \%FM and less FFM than newborn term infants, which is probably partially due to restricted nutrition in utero or in hospital environment (39). It is possible that combination of BIS and US is detecting this BC abnormality whereas US alone is not able to do so due to the very nature of the measurement technique.

Our results support the claim that BIS and US are useful methods of measuring of BC in infants. Skin thickness, subcutaneous fat thickness and \%FM are valuable parameters for assessing and monitoring the nutritional state of the infant. US was introduced for this purpose (10) but currently not widely used. US is able to obviate some of the limitations of the caliper technique in the pediatric population such as age-related inter and intrasubject variation in skinfold compressibility, inability to palpate the fat-muscle interface or to differentiate the layers of skin, differences in the types of calipers used, and pain/trauma factor (38). Petersen et al. reported some degree of difficulty with identification of the dermis-subcutaneous fat interface in preterm infants' skin compared with adult skin using US (10). We did not experience this difficulty, probably because Petersen measured distance between peaks on skin echogram rather than on an actual scan, and that infants in our study were term thus the interface could be more defined. Recently Pineau et al. has validated both US skinfold and BIS measurements in adults against dual-energy X-ray absorptiometry. In that study US has shown very good accuracy, while BIS has shown less accuracy than US but better than air displacement plethysmography (12). BIS predictions of \%FM in infants improve with age compared with simple anthropometric measurements (4) and could benefit pediatric populations if more equations developed for infants after 5 mo of age.

The limitations of this study include the missing data of four skinfolds for 13 infants and, as a result, small numbers in particular sex/age groups; lack of available age-matched equations, necessitating running a full analysis of many equations; and limitation with resources for the study, resulting in absence of reference data for our subjects (notwithstanding the issues with existing reference methods in pediatric population).

In conclusion, high-frequency US measurement of SCTT is a precise and reliable method for assessment of \%FM in breastfed infants. Accurate measurements of SCTT in a wide range of body masses are easily recorded, and the nontraumatic technique allows application of this method even in the smallest infants. BIS, on other hand presents some issues particularly in the earlier mo of life but its performance improves with infant age. While both methods will further benefit from the development of more precise age appropriate equations, a number of the current equations are practical for assessing \%FM in breastfed infants, particularly in longitudinal studies. This study further emphasizes the critical need for development of sex/age specific normative $\mathrm{BC}$ values for assessment of the growth and nutritional status of breastfed infants during the first year of life.

\section{ACKNOWLEDGMENTS}

All authors read and approved the final manuscript. The authors thank all participants for their time and effort.

\section{STATEMENT OF FINANCIAL SUPPORT}

This study was supported by an Australian Postgraduate Award from The University of Western Australia (Australia; Z.G.) and an unrestricted research grant from Medela AG (Switzerland; D.G., P.E.H., A.H., C.T.L.). Author L.C.W. provides fee for service consultancy services to ImpediMed Ltd.

Disclosure: Authors Z.G., A.R.H., C.T.L., P.E.H., and D.T.G. declare no conflict of interest. Medela AG had no role in the design of the study; in the collection, analyses, or interpretation of the data; in the writing of the manuscript, and in the decision to publish the results. Author L.C.W. provides consultancy services to ImpediMed Ltd. ImpediMed Ltd. had no involvement if the inception, conduct of this research or in writing of the manuscript.

\section{REFERENCES}

1. Wells JC, Chomtho S, Fewtrell MS. Programming of body composition by early growth and nutrition. Proc Nutr Soc 2007;66:423-34.

2. Lukaski HC, Johnson PE, Bolonchuk WW, Lykken GI. Assessment of fatfree mass using bioelectrical impedance measurements of the human body. Am J Clin Nutr 1985;41:810-7.

3. Ferreira DM, Souza MN. Bioelectrical impedance spectroscopy for the assessment of body fluid volumes of term neonates. Braz J Med Biol Res 2004;37:1595-606.

4. Lingwood BE, Storm van Leeuwen AM, Carberry AE, et al. Prediction of fat-free mass and percentage of body fat in neonates using bioelectrical impedance analysis and anthropometric measures: validation against the PEA POD. Br J Nutr 2012;107:1545-52.

5. Sesmero MA, Mazariegos M, Pedrón C, Jones J, Solomons NW. Bioimpedance electrical spectroscopy in the first six months of life: some methodologic considerations. Nutrition 2005;21:567-73.

6. Collins CT, Reid J, Makrides M, et al. Prediction of body water compartments in preterm infants by bioelectrical impedance spectroscopy. Eur J Clin Nutr 2013;67 Suppl 1:S47-53.

7. Chan V, Perlas A. Basics of ultrasound imaging. In: Narouze, S, ed. Atlas of Ultrasound-guided Procedures in Interventional Pain Management. LLC: Springer Science+Business Media, 2011:13-9.

8. Ahmad I, Nemet D, Eliakim A, et al. Body composition and its components in preterm and term newborns: a cross-sectional, multimodal investigation. Am J Hum Biol 2010;22:69-75.

9. McLeod G, Geddes D, Nathan E, Sherriff J, Simmer K, Hartmann P. Feasibility of using ultrasound to measure preterm body composition and to assess macronutrient influences on tissue accretion rates. Early Hum Dev 2013;89:577-82.

10. Petersen JR, Petersen S, Serup J. High-frequency ultrasound measurement of dermis and subcutaneous fat in the newborn infant. Skin Res Technol 1995;1:86-9.

11. Ulbricht L, Neves E, Ripka W, Romaneli E. Comparison between body fat measurements obtained by portable ultrasound and caliper in young adults. Annual International Conference of the IEEE Engineering in Medicine and Biology Society (EMBS '12). 2012:1952-5.

12. Pineau J-C, Guihard-Costa A-M, Bocquet M. Validation of ultrasound techniques applied to body fat measurement. Ann Nutr Metab 2007:51:421-7.

13. Gridneva Z, Hepworth AR, Ward LC, Lai CT, Hartmann PE, Geddes DT. Bioimpedance spectroscopy in the infant: effect of milk intake and extra- 


\section{Body composition of breastfed infants}

cellular fluid reservoirs on resistance measurements in term breastfed infants. Eur J Clin Nutr 2016;70:843-51.

14. Matthie JR. Bioimpedance measurements of human body composition: critical analysis and outlook. Expert Rev Med Devices 2008;5:239-61.

15. Gale C, Logan KM, Santhakumaran S, Parkinson JR, Hyde MJ, Modi N. Effect of breastfeeding compared with formula feeding on infant body composition: a systematic review and meta-analysis. Am J Clin Nutr 2012;95:656-69.

16. Carberry AE, Colditz PB, Lingwood BE. Body composition from birth to 4.5 months in infants born to nonobese women. Pediatr Res 2010;68:84-8.

17. Butte NF, Hopkinson JM, Wong WW, Smith EO, Ellis KJ. Body composition during the first 2 y of life: an updated reference. Pediatr Res 2000;47:578-85.

18. Roggero P, Giannì ML, Orsi A, et al. Quality of growth in exclusively breast-fed infants in the first 6 mo of life: an Italian study. Pediatr Res 2010;68:542-4.

19. Gilchrist J. Body composition reference data for exclusively breast-fed infants. Pediatric Academic Society Annual Meeting. Toronto, Canada, 2007: Abstract E-PAS2007:61:7926.1.

20. Bellu R, Ortisi M, Agostoni C, Riva E, Giovannini M. Total body electrical conductivity derived measurement of the body composition of breast or formula-fed infants at 12 mo. Nutr Res 1997;17:23-9.

21. Fomon SJ, Nelson SE. Body composition of the male and female reference infants. Annu Rev Nutr 2002;22:1-17.

22. Fields DA, Gilchrist JM, Catalano PM, Giannì ML, Roggero PM, Mosca F. Longitudinal body composition data in exclusively breast-fed infants: a multicenter study. Obesity (Silver Spring) 2011;19:1887-91.

23. Kushner RF, Schoeller DA, Fjeld CR, Danford L. Is the impedance index (ht2/R) significant in predicting total body water? Am J Clin Nutr 1992;56:835-9.

24. Bocage C. Impedance measurements of body composition in children. Kingston, Jamaica: University of West Indies, 1988.

25. Fjeld CR, Freundt-Thurne J, Schoeller DA. Total body water measured by 18-O dilution and bioelectrical impedance in well and malnourished children. Pediatr Res 1990;27:98-102.

26. Slaughter MH, Lohman TG, Boileau RA, et al. Skinfold equations for estimation of body fatness in children and youth. Hum Biol 1988;60:709-23.
27. Brook CG. Determination of body composition of children from skinfold measurements. Arch Dis Child 1971;46:182-4.

28. Durnin JV, Rahaman MM. The assessment of the amount of fat in the human body from measurements of skinfold thickness. Br J Nutr 1967;21:681-9.

29. Johnston JL, Leong MS, Checkland EG, Zuberbuhler PC, Conger PR, Quinney HA. Body fat assessed from body density and estimated from skinfold thickness in normal children and children with cystic fibrosis. Am J Clin Nutr 1988;48:1362-6.

30. Schmelzle HR, Fusch C. Body fat in neonates and young infants: validation of skinfold thickness versus dual-energy X-ray absorptiometry. Am J Clin Nutr 2002;76:1096-100.

31. Siri W. Body composition from fluid spaces and density: analysis of methods. In: Brozek, J, Henschel, A, eds. Techniques for Measuring Body Composition. Washington, DC: National Academy for Sciences, 1961: 223-44.

32. Lohman T. Body composition in children and youth. In: Boileau, R, ed. Advances in Pediatric Sport Sciences. Champaign, IL: Human Kinetics Publishers, 1984:29-57.

33. Hothorn T, Bretz F, Westfall P. Simultaneous inference in general parametric models. Biom J 2008;50:346-63.

34. Wickham H. ggplot2: Elegant Graphics for Data Analysis. New York: Springer, 2009.

35. Curran-Everett D. Multiple comparisons: philosophies and illustrations. Am J Physiol Regul Integr Comp Physiol 2000;279:R1-8.

36. Bausell R, Li Y-F. Power Analysis for Experimental Research. New York, USA: Cambridge University Press, 2006.

37. Encyclopedia of Mathematics. Kolmogorov-Smirnov test, 2012. (http:// www.encyclopediaofmath.org/index.php?title=Kolmogorov-Smirnov_ test\&oldid=22659.).

38. Kuczmarski RJ, Fanelli MT, Koch GG. Ultrasonic assessment of body composition in obese adults: overcoming the limitations of the skinfold caliper. Am J Clin Nutr 1987;45:717-24.

39. Johnson MJ, Wootton SA, Leaf AA, Jackson AA. Preterm birth and body composition at term equivalent age: a systematic review and meta-analysis. Pediatrics 2012;130:e640-9. 